\section{The Effect of Irrigation Frequency, Phosphorus Fertigation, and Cultivar on Levels of Phenolic Compounds in Sweet Cherries}

\author{
Kelly Ross ${ }^{1}$, Gerry Neilsen, and Denise Neilsen \\ Summerland Research and Development Centre, Summerland, BC VOH 1Z0, \\ Canada
}

Additional index words. anthocyanins, flavonols, Prunus avium, tartaric esters, total phenolics

\begin{abstract}
This work examined the effect of irrigation frequency and phosphorus (P) fertigation on the levels of phenolic compounds present in two sweet cherry cultivars, 'Skeena' and 'Cristalina', over three growing seasons (2012-14). Two irrigation treatments were tested: a high irrigation frequency (I1) and a low irrigation frequency (I2). Both irrigation treatments applied the same quantities of water [100\% evapotranspiration (ET)], but the high irrigation frequency applied water four times daily (0300, 0900,1500 , and $2100 \mathrm{HR}$ ) whereas the low irrigation frequency was applied at one time (0900 HR) every second day. Three soil management treatments were investigated, including 1) an unmulched control receiving no $P, 2$ ) a $10-\mathrm{cm}$ waste wood mulch receiving no $P$, and 3) a treatment involving annual fertigation of $20 \mathrm{~g} P /$ tree at full bloom as ammonium polyphosphate. It was determined that cultivar was the most important factor affecting levels of phenolic compounds in sweet cherries, with generally greater levels associated with 'Skeena'. The effect of different irrigation and fertilization strategies showed less promising results in terms of influencing levels of phenolic compounds. Both severe and mild water stress did not show an appreciable influence on increasing levels of phenolic compounds in cherries. Furthermore, severe water stress, which occurred during 2012, was associated with the lowest annual concentration of phenolic compounds and an economically unacceptable reduction in fruit size. Phosphorus fertigation influenced cherry phosphorus status positively by increasing leaf and fruit $P$ concentrations consistently, yet these fruit exhibited lower levels of phenolic compounds.
\end{abstract}

There is growing interest in consuming a diet enriched with naturally occurring phytochemicals, such as a diet high in fruits and vegetables. High intake of fruit and vegetables is reported to be beneficial to human health as a result of the reductions in the risks of developing cancer (Boivin et al., 2009) and cardiovascular disease (Erdman et al., 2007). Phytochemicals with antioxidant activity reduce the detrimental effects of reactive oxygen species produced from normal plant metabolic processes (Munns and Tester, 2008) and are stimulated when plants encounter environmental stresses (Atkinson et al., 2005). As such, the biochemical and molecular mechanisms that plants have developed to ensure their growth result in the acquisition and formation of components that may benefit human health. Consumption of phytochemical/bioactive compounds present in plants may limit oxidative damage in human cells (Foyer and Fletcher, 2001; Li et al., 2007). Therefore, supplementing our body's capability to eliminate free radicals by the consumption of foods high in antioxidants

Received for publication 14 June 2018. Accepted for publication 7 Aug. 2018.

${ }^{1}$ Corresponding author. E-mail: kelly.ross2@canada. ca.

HortScience Vol. 53(10) October 2018
However, despite the recent appearance of many new sweet cherry cultivars, there have been relatively few studies determining the effects of sweet cherry cultivar on levels of phenolic compounds (Ballistreri et al., 2013; Liu et al., 2011). Seasonal variation has been shown to affect cherry yield, crop load, and quality (Caprio and Quamme, 2006; Engin et al., 2009; Measham et al., 2012; Neilsen et al., 2014). The work of Usenik et al. (2010) noted that the canopy leaf area-to-fruit ratio influenced fruit color, fruit mass, total soluble solids, and the sugars-to-acid ratio of sweet cherries. It has been reported that lower crop loads are related to greater levels of phenolic compounds in apples (Stopar et al., 2002). Also, in general, crop production factors such as irrigation and fertilization have been reported to affect the chemical composition of fruits, which impacts nutritional and bioactive compositions along with sensory quality (taste, color, texture/firmness) at harvest and during shelf life (Ali et al., 2012; Ferretti et al., 2010; Kader, 2002). Regulated water stress has been proposed as a mechanism to achieve high levels of bioactive compounds in fruits (Atkinson et al., 2005), yet there have been few studies that have investigated the potential role of cultural and environmental factors on levels of phenolic compounds in cherries. A recent review called for increased research to clarify the impact of environmental stresses on crop quality (Wang and Frei, 2011).

In the irrigated fruit-growing region of the Pacific Northwest of North America, extreme climatic events including drought are expected consequences of global climate change (Neilsen et al., 2006). This has stimulated interest in the consequences of various conservation irrigation strategies on plant performance, including fruit mineral concentrations (Neilsen et al., 2015). Limited information is available concerning how novel irrigation approaches affect the production of secondary metabolites in fruit despite the inevitability of water shortage. Furthermore, the widespread adoption of altered, potentially more stressful, conservation irrigation methods is of emerging importance (Ripoll et al., 2014). Recent research on sweet cherry, a crop of growing importance in the region, has identified several nutrient and water management strategies, including $\mathrm{I} 1$ and $\mathrm{P}$ fertigation (Neilsen et al., 2010, 2014), that can improve cherry fruit yield and quality, but effects on levels of different types of phenolic compounds in cherries have not been assessed.

The objective of this study was to determine the effects of irrigation frequency, $\mathrm{P}$ fertigation, and cultivar (Skeena and Cristalina) on the size (quality parameter) and levels of different types of phenolic compounds (total phenolics, tartaric esters, flavonols, and total anthocyanins) of sweet cherries at harvest. In addition, this work provides data on the levels of phenolic compounds for two cherry cultivars, Skeena and Cristalina, grown in the Okanagan region of British Columbia as affected by different 
irrigation and fertilization strategies that can serve as a resource for other comparative work.

\section{Materials and Methods}

General orchard information. This study was conducted over three growing seasons in a sweet cherry (Prunus cerasus $\times$ Prunus canescens) orchard of 'Cristalina' and 'Skeena' cultivars. The trees were planted on Gisela 6 rootstock in Mar. 2005 at the Summerland Research and Development Center in Summerland, British Columbia, Canada. The orchard was maintained in a split-split plot experimental design with two main plot irrigation treatments, two cultivars as subplots, and three soil management treatments as sub-subplots with six replicates in 2006-14. Sub-subplots, the smallest experimental unit, consisted of two measurement trees separated from adjacent subplots within the row by a shared guard tree at each end. Trees were planted at a spacing of $2 \mathrm{~m}$ (between trees) $\times 4 \mathrm{~m}$ (between rows), representing a planting density of 1250 trees/ha.

Irrigation treatments. For nine growing seasons (2006-14), irrigation was scheduled to replace $100 \%$ of the previous day's evapotranspiration (ET) based on evaporation from an electronic atmometer (ET gauge Co., Loveland, CO) according to Parchomchuk et al. (1996), modified by crop coefficients. A crop coefficient curve, based on expected seasonal canopy development, was fitted to data from Allen et al. (1998). The two tities of water $(100 \%$ ET) but at either I1 or I2. I1 irrigation was applied four times daily irrigation treatments applied the same quan-

(0300, 0900, 1500, and $2100 \mathrm{HR})$ and $\mathrm{I} 2$ irrigation was applied every second day at 0900 HR. Irrigation was applied through $4 \times$ $4-\mathrm{L} \cdot \mathrm{h}^{-1}$ drip emitters located in two lines separated by $0.6 \mathrm{~m}$ on either side of the tree rows, with emitters separated by $0.6 \mathrm{~m}$ in a square pattern centered on the tree. Irrigation was generally applied annually from mid April to mid October.

Fertigation strategy. Three soil management treatments were maintained throughout the experiment, including an unmulched control receiving no $\mathrm{P}$; a waste wood mulch, which was maintained at a $10-\mathrm{cm}$ depth by periodic additions as it decomposed over a 2-m wide strip centered on the tree row and also receiving no $\mathrm{P}$; and a treatment involving annual fertigation of $20 \mathrm{~g} \mathrm{P} /$ tree at full bloom as ammonium polyphosphate $(10 \mathrm{~N}-15 \mathrm{P}-$ $0 \mathrm{~K})$. The $\mathrm{P}$ fertigation treatment was of particular interest because this treatment had been shown previously to augment tree $\mathrm{P}$ status and affect fruit maturity when fruit production was well established in the planting (2009-11) (Neilsen et al., 2014). The mulch treatment was selected for its potential to improve soil moisture content, and soil diffusion and plant uptake of $\mathrm{P}$.

For all treatments, a 2-m-wide weed-free herbicide strip was maintained in the tree row to minimize the detrimental consequences of competition from orchard floor vegetation. To optimize tree nutrition, all treatments received annual fertigation of nitrogen $(\mathrm{N})$, potassium (K), and boron (B) from 2005-14. $\mathrm{N}$ was applied daily for 8 weeks, commencing immediately postbloom as calcium nitrate $(15.5 \mathrm{~N}-0 \mathrm{P}-0 \mathrm{~K})$ to supply $20 \mathrm{~g} \mathrm{~N} /$ tree/

Table 1. Summary of statistically significant interactions ${ }^{\mathrm{z}}$ among irrigation (I), P fertigation (PF), and cultivar (CV) for fruit weight and phenolic compounds during the 2014 growing season.

\begin{tabular}{|c|c|c|c|c|c|c|}
\hline Interaction & Fruit wt & $\begin{array}{l}\text { Total phenolics } \\
\text { (Folin-Ciocalteu } \\
\text { method) }\end{array}$ & $\begin{array}{l}\text { Total phenolics } \\
\text { (Glories method) }\end{array}$ & $\begin{array}{l}\text { Tartaric } \\
\text { esters }\end{array}$ & Flavonols & $\begin{array}{c}\text { Total } \\
\text { anthocyanins }\end{array}$ \\
\hline$\overline{\mathrm{I} \times \mathrm{CV}}$ & NS & NS & NS & NS & NS & NS \\
\hline $\mathrm{I} \times \mathrm{PF}$ & NS & NS & NS & NS & NS & NS \\
\hline $\mathrm{PF} \times \mathrm{CV}$ & $* * * *$ & $* * *$ & $* * *$ & $* * *$ & $* * * *$ & $*$ \\
\hline $\mathrm{I} \times \mathrm{CV} \times \mathrm{PF}$ & $*$ & * & $*$ & $* *$ & NS & NS \\
\hline
\end{tabular}

${ }^{\mathrm{z}}$ Significant interactions between main effects at $P \leq 0.05(*), P \leq 0.01(* *), P \leq 0.001(* * *)$, or $P \leq$ $0.0001(* * * *)$; or not significant (NS). year. $\mathrm{K}$ was applied daily for about 4 weeks starting in early June as potassium chloride $(0 \mathrm{~N}-0 \mathrm{P}-50 \mathrm{~K})$ to supply $20 \mathrm{~g} \mathrm{~K} /$ tree/year. Boron was coapplied with $\mathrm{K}$ as Solubor $(20 \% \mathrm{~B})$ at a rate of $0.17 \mathrm{~g} \mathrm{~B} /$ tree/year. The soil at the experimental site was a coarsetextured Skaha loamy sand, an Aridic Haploxeroll planted extensively in orchards in southern British Columbia (Wittneben, 1986). Standard commercial production practices were used to control insects and diseases as required (British Columbia Ministry of Agriculture and Lands, 2010).

Leaf and fruit sample collection. Throughout the nine growing seasons, the plots were maintained in the described experimental design and measurements were made on tree vigor, yield, and fruit quality as detailed in previous publications (Neilsen et al., 2010, 2014). Pertinent to this article are the final three growing seasons (2012-14), when fruit sampling was undertaken to investigate the effects of $\mathrm{P}$ fertigation, irrigation frequency, and cultivar on the levels of different types of phenolic compounds in sweet cherries. In 2012, fruit samples were collected from only two of the three soil management treatments ( $\mathrm{P}$ and no $\mathrm{P}$ control), and the whole block was subjected to a preharvest water stress from 30 June until 23 July as a consequence of failure of the automatic irrigation system. All treatments were sampled in 2013 and 2014, and there were no irrigation anomalies during these years. Fruit were harvested for each cultivar according to packinghouse recommendations for the Summerland district. For 'Cristalina', this was day of year (DOY) 198, 191, and 189 (16, 10, and 8 July 2012-14, respectively) and for Skeena this was DOY 214, 211, and 209 (1 Aug. and 30 and 28 July, 2012-14, respectively). Composite samples comprising 30 leaves/plot were collected from the mid-third portion of extension shoots for all plots on the harvest date for each cultivar.

Phosphorus content assessment. Leaf and fruit $\mathrm{P}$ concentrations were measured annually for all plots. In preparation for $\mathrm{P}$ analysis of leaf samples, the leaves were oven-dried at $65{ }^{\circ} \mathrm{C}$ and ground in a stainless steel mill. In preparation for $\mathrm{P}$ analysis of cherry fruit

Table 2. Average fruit weight and dry weight concentration of selected phenolic compounds as affected by high-frequency (I1) and low-frequency (I2) irrigation during the 2012-14 growing seasons.

\begin{tabular}{|c|c|c|c|c|c|c|}
\hline $\begin{array}{l}\text { Irrigation } \\
\text { treatment }\end{array}$ & $\begin{array}{c}\text { Fruit } \\
\text { wt (g) }\end{array}$ & $\begin{array}{l}\text { Total phenolics } \\
\text { (Folin-Ciocalteu } \\
\text { method, mg gallic } \\
\text { acid eq/100 g dry wt) }\end{array}$ & $\begin{array}{l}\text { Total phenolics } \\
\text { (Glories method, mg gallic } \\
\text { acid eq/100 g dry wt) }\end{array}$ & $\begin{array}{l}\text { Tartaric esters } \\
\text { (mg caffeic acid } \\
\text { eq/100 g dry wt) }\end{array}$ & $\begin{array}{c}\text { Flavonols } \\
\text { (mg quercetin } \\
\text { eq/100 g dry wt) }\end{array}$ & $\begin{array}{c}\text { Total anthocyanins } \\
\text { (cyanidin 3-rutinoside/100 g } \\
\text { dry wt) }\end{array}$ \\
\hline \multicolumn{7}{|l|}{2012} \\
\hline I2 & 8.1 & 485 & 440 & 193 & 97 & 106 \\
\hline Significance & NS & NS & NS & NS & NS & NS \\
\hline \multicolumn{7}{|l|}{2013} \\
\hline Significance & $* *$ & NS & NS & NS & NS & NS \\
\hline \multicolumn{7}{|l|}{2014} \\
\hline I1 & 10.5 & 643 & 650 & 218 & 171 & 381 \\
\hline $\mathrm{I} 2$ & 10.5 & 720 & 666 & 224 & 173 & 344 \\
\hline Significance & NS & NS & NS & NS & NS & NS \\
\hline
\end{tabular}

${ }^{\mathrm{z}} \mathrm{I} 1$ irrigation applied four times daily or once every second day (I2) with the same quantities of water (100\% ET replacement). $\mathrm{NS}=$ paired means not significantly different. 
samples, a 60-fruit sample was collected from each plot and the cherries were destemmed, pitted, and added to a blender with water in a $1: 1$ fruit-to-water ratio $(w / w)$. This resulted in a fruit slurry that was subsequently freeze-dried, which allowed for a homogeneous freeze-dried product to be obtained. The freeze-dried cherry material was then placed in polyethylene bags and its particle size was reduced by crushing the freeze-dried material into a powder with a marble rolling pin. For P analysis, $0.500 \pm$ $0.002 \mathrm{~g}$ ground dried leaf or fruit sample were weighed into crucibles. Lids were put on the crucibles and the crucibles were "ashed" in a programmable muffle furnace. The samples were ashed at $525{ }^{\circ} \mathrm{C}$ for $8 \mathrm{~h}$. To the ashed crucibles, $10 \mathrm{~mL}$ of $1.2 \mathrm{~N} \mathrm{HCl}$ was added and allowed to sit for $60 \mathrm{~min}$. Samples were analyzed for P using an ICP-OES spectrophotometer (Spectroblue TI; Spectro, Kleve, Germany). P results for the leaf samples were expressed on a dry weight basis whereas results for cherry samples were expressed on a fresh weight basis.

Phenolics content assessment. A randomly harvested 100-fruit subsample for each sampled plot was used to determine average fruit weight. For measurement of levels of phenolic compounds present in the cherries, another randomly harvested 100fruit subsample for each sampled plot was used to obtain a composite sample from which phenolic compounds were extracted. Before extraction, cherries were destemmed, pitted, and added to blender with water in a 1:1 fruit-to-water ratio $(\mathrm{w} / \mathrm{w})$. This resulted in a fruit slurry that was subsequently freezedried in the same manner as noted earlier. The freeze-dried cherry powder was then subjected to solvent extraction, and the extracts were assessed to determine the types and levels of phenolic compounds present because studies have shown that phenolic compounds derived from plants are effective antioxidants (Rice-Evans et al., 1997). Total phenolics content was assessed using both the Folin-Ciocalteu and Glories methods. The use of the Glories method also allowed for the determination of levels of total tartaric esters, flavonols, and anthocyanins. The extracts used for testing in these methods were obtained using a procedure based on the work of Velioglu et al. (1998). An aliquot of $1 \mathrm{~g}$ sample (freeze-dried cherry powder) was weighed into a centrifuge tube and $20 \mathrm{~mL}$ $70 \% \mathrm{MeOH}$ was added to the tube $(1: 20$ ratio). Tubes were vortexed to ensure wetting of all solids, then were placed on a shaker (VWR 3500 Analog Shaker; VWR, Mississauga, ON) and shaken on shaker speed 4 for $30 \mathrm{~min}$. The tubes were then centrifuged at $\approx 10,000 \mathrm{~g}$ for $10 \mathrm{~min}$. The resulting supernatant was filtered under vacuum through Whatman No. 1 paper (VWR) on a Buchner funnel into a $125-\mathrm{mL}$ filtering flask. The supernatant was collected and these samples were diluted further with $70 \%$ methanol, if required, to be within the standard curve.

Measurement of total phenolics using the Folin-Ciocalteu colorimetric method was based on the procedure described by Singleton and Rossi (1965). Briefly, $50 \mu \mathrm{L}$ sample extract or gallic acid standard was added to a test tube along with $150 \mu \mathrm{L}$ MilliQ water. The system was vortexed to ensure adequate mixing, then $1 \mathrm{~mL}$ Folin-Ciocalteu reagent (Sigma Aldrich, St. Louis, MO) was added. The system was vortexed and $0.8 \mathrm{~mL}$ of $\mathrm{Na}_{2} \mathrm{CO}_{3}$ (Sigma Aldrich) solutions $(75 \mathrm{~g} / \mathrm{L})$ was added. The system was vortexed again to ensure adequate mixing, then was allowed to sit for $60 \mathrm{~min}$ before reading absorbance. Quantification was determined based on a standard curve for gallic acid by measuring absorbance at $765 \mathrm{~nm}$ on a spectrophotometer (Cary 50; Agilent Technologies, Mississauga, $\mathrm{ON})$. The total amount of phenolic content was expressed as milligrams gallic acid equivalent per gram sample on a dry weight basis. Experiments were performed in duplicate. Measurement of total phenolics, tartaric esters, flavonols, and anthocyanins using the Glories method was performed using a procedure based on the method provided by Harrison et al. (2013). An aliquot of $0.1 \mathrm{~mL}$ sample extract or standard was added to a test tube. Gallic acid, caffeic acid, quercetin, and cyanidin-3rutinoside were used as the standards for quantification of total phenolics, tartaric esters, flavonols, and anthocyanins, respectively. To the sample or standard, $0.1 \mathrm{~mL}$ $0.1 \% \mathrm{HCl}$ in $95 \%$ EtOH along with $1.82 \mathrm{~mL}$ $2 \% \mathrm{HCl}$ was added. The system was vortexed and allowed to sit for $\approx 15$ min before reading the absorbance. Quantification was determined based on a standard curve for each standard by measuring absorbance at $280,320,360$, and $520 \mathrm{~nm}$ on a spectrophotometer (Cary 50; Agilent Technologies) for determination of total phenolics, tartaric esters, flavonols, and anthocyanins, respectively. The total amount of phenolic content was expresses at milligrams standard equivalent per gram sample on a dry weight basis. Experiments were performed in duplicate.

Soil moisture measurements. Volumetric soil moisture was measured using depthintegrated $(0-20 \mathrm{~cm})$ time domain reflectometry periodically from June to Oct. 2012-14 (Topp and Reynolds, 1998). Volumetric soil moisture content was expressed as percent total available water (TAW) averaged over the 0 - to $20-\mathrm{cm}$ depth. TAW $=(\mathrm{SW}-\mathrm{PWP} /$ $(\mathrm{FC}-\mathrm{PWP}) \times 100$, where $\mathrm{SW}$ is percent volumetric soil moisture content, PWP is soil moisture content at the permanent wilting point (15 bars, $8 \%$ volumetric soil moisture content), and FC is soil moisture content after soil drainage ( 0.1 bar, $18 \%$ volumetric soil moisture content). Moisture measurements were made at 24 locations [both cultivars $\times$ two irrigation treatments (I1 and I2) $\times$ two soil management treatments (no P control and mulch) $\times$ three replicates]. Probes were located $0.3 \mathrm{~m}$ from the south side of the measurement trees midway between the two emitters. Measurements were made just before the $0900 \mathrm{HR}$ irrigation of the I 2 irrigation, which maximized the difference between the I1 and I2 irrigation treatments. In 2014, midday stem water potential measurements were made on DOY 182 (12 July), 205 (25 July), and 216 (5 Aug.). Measurements were made between 1100 and 1400 HR on the 24 plots where soil moisture measurements were made. Each time, midday stem water potential was determined on three leaves per treatment and replicate after shielding the leaf with black plastic covered with aluminum foil for 2 to $3 \mathrm{~h}$ to avoid leaf temperature increase during measurement of water potential using a pressure chamber model 610 (PMS Instrument Co., Albany, OR) (McCutchan and Shackel, 1992).

Statistical analysis. Analysis of variance was performed on all measured soil and plant variables using the GLM procedure (SAS, 2006). The analysis was undertaken separately for each year because of differences in plots sampled and environmental conditions
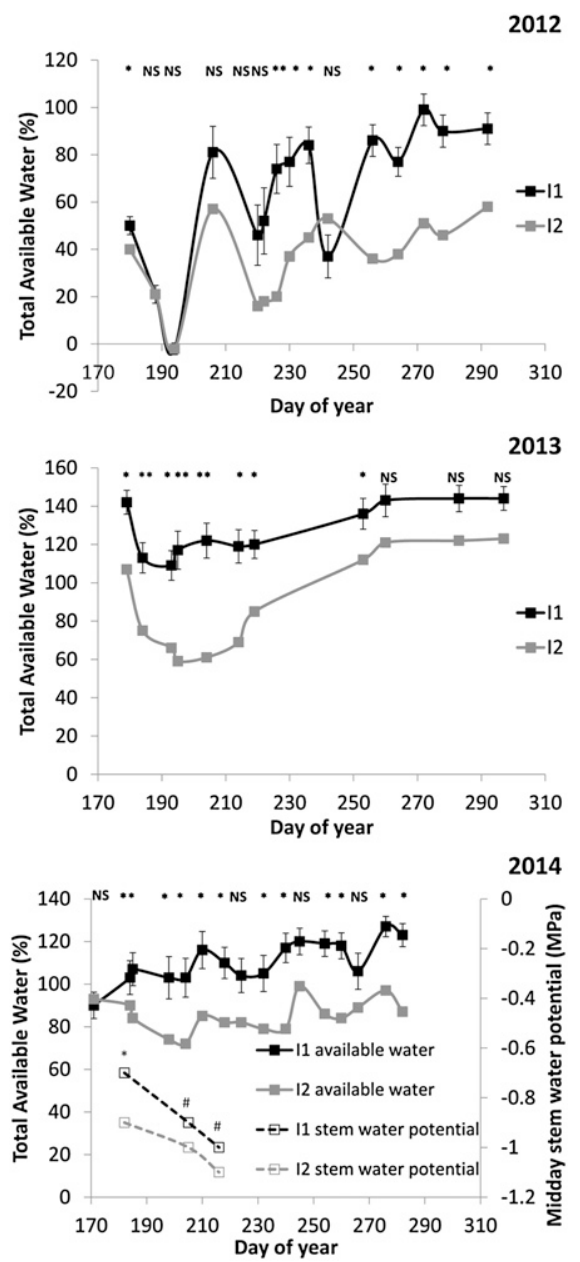

Fig. 1. Average volumetric water content $(0-20$ $\mathrm{cm}$ depth) expressed as percent total available water and SE for high-frequency (I1) and lowfrequency (I2) irrigation treatments for the 2012-14 growing seasons. I1 irrigation was applied four times daily; I2 irrigation was applied every second day with the same quantities of water (100\% ET replacement). Average midday stem water potential measurements in 2014. Irrigation treatments significantly different at $P=0.01(* *), P=0.05(*)$, or $P=0.10$ (\#); or not significantly different (Ns). $\mathrm{SE}$ for the treatment means indicated on I1 treatment 
in 2012. Volumetric soil measurement and leaf water potential measurements were analyzed on 24 plots [two cultivars $\times$ two irrigation frequencies (I1 and I2) $\times$ two soil management treatments (no $\mathrm{P}$ control and mulch) $\times$ three replicates]

\section{Results and Discussion}

In 2012 and 2013, statistically significant effects were observed only for main effect treatments (irrigation, P fertigation, and cultivar). Significant interactions were observed only in 2014 (Table 1). That year, there was a significant two-way interaction between $\mathrm{P}$ fertigation and cultivar for fruit size and the concentration of all phenolic compounds, and a significant three-way interaction for fruit weight, total phenolics (both methods), and tartaric acid concentrations. These complex three-way interactions are not discussed subsequently.

Irrigation treatments. Levels of the different types of phenolic compounds [total phenolics (Folin-Ciocalteu method), total phenolics (Glories method), tartaric esters, flavonols, and total anthocyanins] were unaffected in 2012-14 by variation in irrigation frequency (Table 2). As noted earlier, there were no interactions for irrigation effects over the three growing seasons. I1 had been previously advantageous, improving initial growth and establishment of these sweet cherries (Neilsen et al., 2010) as a consequence of maintaining greater surface soil moisture content when measured just before I2 irrigation. The same favorable moisture regime was maintained for I2 trees in the three growing seasons during which fruit phenolic concentrations were measured (Fig. 1). However, in 2012, there was a mechanical problem with the automated irriga- tion system that occurred during netting of the block to avoid bird damage to the earlyripening 'Cristalina' cherries at the end of June. As a consequence, both treatments experienced low soil water contents (expressed as percent available water), with values reaching zero available water (the permanent wilting point) on DOY 194 (12 July) before correction of the problem on DOY 205 (23 July) (Fig. 1). Thus, both irrigation treatments were subjected to considerable water stress in 2012 during the critical preharvest period. In contrast, during 2013-14, I1 maintained soil moisture readings at or greater than field capacity whereas I2 resulted in available water content ranging from $60 \%$ to $80 \%$ and $70 \%$ to $80 \%$ of maximum immediately preharvest during 2013-14, respectively. This was assumed to represent a mild water stress difference between treatments during these years, and contrasts with the severe stress observed for both treatments in 2012. Midday stem water potentials, as measured on $3 \mathrm{~d}$ in 2014, when significant soil moisture differences were observed between I1 and I2, confirmed this. There were significant differences $(P \leq 0.10)$ between stem potential for I1 trees $(-0.7$ to $-1.0 \mathrm{MPa})$ relative to $\mathrm{I} 2$ trees $(-0.8$ to $-1.1 \mathrm{MPa}$ ) (Fig. 1). It is noteworthy that midday stem water potential declined later in the growing season despite TAW remaining relatively constant. This is consistent with measurements made on daily drip-irrigated 'Ambrosia' apple and has been attributed to plant water stress being affected by high evaporative demand midsummer and reduced soil hydraulic conductivity rather than reduced soil water potential (Neilsen et al., 2016). None of the values for either treatment approached midday stem potential values of $-1.5 \mathrm{MPa}$ associated previously with detri- mental stress in sweet cherry (Neilsen et al., 2017). Unfortunately, stem potential measurements were made only in a single year. It would have been informative to have performed plant water measurements during the period of severe water stress in 2012 .

No differences in levels of the different types of phenolic compounds were observed between I1 and I 2 throughout the study, and concentrations of phenolic compounds were at their lowest values in 2012, when both treatments were significantly water stressed. In 2012, average fruit size over all treatments was a commercially unacceptable $8.3 \mathrm{~g}$ compared with $11.3 \mathrm{~g}$ in 2013 and $10.5 \mathrm{~g}$ in 2014 (Table 2). Thus, there would appear to be limited scope to manipulate cherry fruit phenolic compound levels by application of mild or severe water stress.

$P$ fertigation. All measurements of levels of the different types of phenolic compounds in cherry fruit were affected significantly by the soil management treatment involving $\mathrm{P}$ fertigation (Table 3). In 2012, when only control and P-fertilized fruit were assessed, the measured levels of phenolic compounds were always reduced in harvested fruit that had received P. Similarly, in 2013, Pfertigated fruit had lower levels of phenolic compounds than fruit from mulch and control treatments, which did not receive $\mathrm{P}$. The single exception was flavonol concentration, which did not differ between control and Pfertigated fruit. In 2014, there was a significant cultivar-by-soil management interaction with 'Cristalina', but not 'Skeena', fruit exhibiting the pattern of the two previous years, with minimum levels of phenolic compounds occurring in P-fertigated fruit (Tables 1 and 3). In contrast, for 'Skeena', all concentrations of phenolic compounds in P-fertigated fruit exceeded values for control

Table 3. Average fruit weight and dry weight concentration of selected phenolic compounds as affected by P fertigation during the $2012-14$ growing seasons.

\begin{tabular}{|c|c|c|c|c|c|c|}
\hline$P$ treatments & $\begin{array}{l}\text { Fruit } \\
\text { wt }(\mathrm{g})\end{array}$ & $\begin{array}{l}\text { Total phenolics } \\
\text { (Folin-Ciocalteu } \\
\text { method, mg gallic acid } \\
\text { eq/100 g dry wt) }\end{array}$ & $\begin{array}{l}\text { Total phenolics } \\
\text { (Glories } \\
\text { method, } \\
\text { mg gallic acid } \\
\text { eq/100 g dry wt) }\end{array}$ & $\begin{array}{l}\text { Tartaric esters } \\
\text { (mg caffeic acid } \\
\text { eq/100 g dry wt) }\end{array}$ & $\begin{array}{l}\text { Flavonols } \\
\text { (mg quercetin } \\
\text { eq/100 g dry wt) }\end{array}$ & $\begin{array}{c}\text { Total anthocyanins } \\
\text { (cyanidin 3-rutinoside/100 g } \\
\text { dry wt) }\end{array}$ \\
\hline No $P$ & 8.2 & 523 & 473 & 203 & 107 & 134 \\
\hline $\mathrm{P}$ & 8.3 & 464 & 425 & 192 & 94 & 90 \\
\hline Significance & NS & $* * *$ & ** & * & ** & $* * * *$ \\
\hline No $P$ & 11.2 & $629 a$ & $540 \mathrm{a}$ & $213 \mathrm{a}$ & $110.3 \mathrm{ab}$ & $289 \mathrm{a}$ \\
\hline $\mathrm{P}$ & 11.6 & $570 \mathrm{~b}$ & $491 \mathrm{~b}$ & $199 \mathrm{~b}$ & $110 \mathrm{~b}$ & $239 \mathrm{~b}$ \\
\hline Significance & NS & $* * *$ & $* *$ & * & $* *$ & $* * * *$ \\
\hline \multicolumn{7}{|l|}{2014} \\
\hline \multicolumn{7}{|l|}{ Cristalina } \\
\hline Mulch & $9.2 \mathrm{~b}$ & $653 \mathrm{a}$ & $603 \mathrm{a}$ & $198 \mathrm{a}$ & 166 a & $354 \mathrm{a}$ \\
\hline No $P$ & $9.2 \mathrm{~b}$ & $674 \mathrm{a}$ & $621 \mathrm{a}$ & 198 a & $172 \mathrm{a}$ & $386 \mathrm{a}$ \\
\hline Interaction significance ${ }^{z}$ & $* * * *$ & $* * *$ & $* * *$ & $* * *$ & $* * * *$ & $*$ \\
\hline Interaction $\mathrm{SE}$ & 0.4 & 22.9 & 23.8 & 6.7 & 6.5 & 27.9 \\
\hline
\end{tabular}

${ }^{2}$ Significant interaction between $P$ treatments and cultivar in 2014 .

Means significantly different at $P \leq 0.05(*), P \leq 0.01(* *), P \leq 0.001(* * *)$, or $P \leq 0.0001(* * * *)$; or not significantly different (NS). For P treatments, means are NS when followed by the same letter within cultivars. 
fruit. Both measures of 'Skeena' total phenolics and flavonols were similar to mulched fruit. Concentrations of tartaric esters were greater and anthocyanin concentrations were lower in P-fertigated fruit relative to fruit from trees that had been mulched. Fruit were a similar size between and among treatments in both 2012 and 2013 (Table 3). In 2014, there was an interaction between cultivar and soil management treatments for fruit size (Table 1) as a result of P-fertigated fruit being largest for 'Cristalina' and smallest for 'Skeena'. The small 'Skeena' fruit in 2014 may have resulted in greater fruit levels of phenolic compounds reversing the patterns observed during previous years.

$P$ fertigation at bloom time was effective at augmenting cherry tree $\mathrm{P}$ status as indicated by consistent increases in midsummer leaf $\mathrm{P}$ and fruit $\mathrm{P}$ concentrations at harvest in trees receiving spring $\mathrm{P}$ applications relative to mulched and control trees, which received standard NKB fertigation without $P$ (Table 4). Fertigation of high rates of $\mathrm{P}$ coincident with bloom was shown previously to be effective and desirable by increasing leaf and fruit $\mathrm{P}$ concentration while improving establishment of sweet cherry in this block (Neilsen et al., 2010). Delayed crop maturity - as indicated by reduced harvest color and soluble solids contents, and greater stem pull force-were other previously observed consequences of $\mathrm{P}$ fertigation. In general, the data indicate that $\mathrm{P}$ fertigation acts to reduce levels of phenolic compounds at harvest, which may reflect the previously observed delayed cherry maturity associated with $\mathrm{P}$ applications. Improved subtropical peach fruit quality and elevated fruit phytochemical composition has been associated recently with low $\mathrm{N}$ fertilization rates, although effects varied by cultivar (Vashisth et al., 2017). In a previous study involving $\mathrm{P}$ fertigation of apple cultivars, elevated fruit $\mathrm{P}$ was associated with reduced incidence of water core on some cultivars at harvest, increased resistance to browning, and elevated antioxidant activities (Neilsen et al., 2008). This collective information is further evidence that fertilization can influence the levels of phenolic compounds in fruit, but there are likely to be important differences across horticultural crops and cultivars.

Cultivar. The levels of phenolic compounds were consistently greater in 'Skeena' compared with 'Cristalina' for 2012-14 (Tables 3 and 5). These concentration differences were independent of fruit size because they were measured regardless whether 'Skeena' cherries were smaller (2012), larger (2014), or the same size (2013) as 'Cristalina' cherries. Only anthocyanin concentrations differed from this pattern, with similar values between cultivars during the first two growing seasons and greater values associated with 'Skeena' cherries in 2014, the last year of the study. Similarities in anthocyanin concentration were expected because harvest time for each dark-skinned cultivar each year was based on commercial practices, which seeks to maximize soluble solids and fruit size by delaying fruit harvest until achievement of a darker skin color.

In this study, cultivar was an important factor in the variation of levels of phenolic

Table 4. Leaf and fruit $\mathrm{P}$ concentration as affected by $\mathrm{P}$ treatments, 2012-14.

\begin{tabular}{lccccccc}
\hline & \multicolumn{3}{c}{ Leaf $\mathrm{P}(\mathrm{g} / \mathrm{kg}$ dry wt) } & & \multicolumn{3}{c}{ Fruit P (mg/100 g fresh wt) } \\
\cline { 2 - 4 } \cline { 7 - 8 } P treatments & 2012 & 2013 & 2014 & & 2012 & 2013 & 2014 \\
\hline Mulch & $\mathrm{nm}^{\mathrm{z}}$ & $2.2 \mathrm{~b}$ & $0.23 \mathrm{~b}$ & & $\mathrm{~nm}^{\mathrm{z}}$ & $26.0 \mathrm{~b}$ & $20.5 \mathrm{~b}$ \\
No P & $2.2 \mathrm{~b}$ & $2.2 \mathrm{~b}$ & $0.22 \mathrm{~b}$ & & $21.8 \mathrm{~b}$ & $24.7 \mathrm{~b}$ & $19.0 \mathrm{c}$ \\
$\mathrm{P}$ & $3.3 \mathrm{a}$ & $3.3 \mathrm{a}$ & $0.28 \mathrm{a}$ & & $25.7 \mathrm{a}$ & $29.9 \mathrm{a}$ & $22.7 \mathrm{a}$ \\
Significance & $* * * *$ & $* * * *$ & $* * * *$ & & $* * * *$ & $* * * *$ & $* * * *$ \\
\hline
\end{tabular}

${ }^{\mathrm{z}}$ No samples collected for mulch treatments in 2012.

Means within columns followed by different letters are significantly different at $P \leq 0.0001$.

compounds in cherries, as has been reported previously (Serradilla et al., 2017). 'Cristalina' has been identified previously as a darkskinned sweet cherry cultivar with high antioxidant activity and anthocyanin content (Diaz-Mula et al., 2008). 'Skeena' is also a dark-skinned cultivar, but was found to have elevated total phenolic, tartaric ester, and flavanol concentrations relative to 'Cristalina', possibly as a result of its much longer growing season. This suggests cultivar is an important variable influencing levels of phenolic compounds in sweet cherries, and that skin color and associated anthocyanin concentration are not the only predictors of levels of phenolic compounds in cherries, because colorless phenolics (Gao and Mazza, 1995) contribute to levels of phenolic compounds.

\section{Conclusions}

Cultivar was the most important factor affecting levels of phenolic compounds in sweet cherries in this study, with generally greater levels associated with 'Skeena', a dark-skinned cultivar with a longer growing season, than 'Cristalina'. This suggests that incorporating assessment of levels of phenolic compounds into cherry breeding programs would offer the best prospects for identifying a quality cherry with high levels of phenolic compounds and therefore antioxidant activities. Manipulation of environmental factors associated with water and nutrient management was less promising. Neither severe nor mild water stress had much influence on levels of phenolic compounds in cherries, with severe water stress (as occurred during 2012) associated with lowest annual concentration of phenolic compounds and an economically unacceptable reduction in fruit size. $\mathrm{P}$ fertigation was highly effective at increasing cherry $\mathrm{P}$ status, elevating leaf and fruit $\mathrm{P}$ concentrations consistently. However, these fruit had lower levels of phenolic compounds, possibly indicating a role for $\mathrm{P}$ in the retardation of fruit maturity and the accumulation of phenolic compounds and antioxidant activity. Finally, this work

Table 5. Average fruit weight and dry weight concentrations of selected phenolic compounds as affected by sweet cherry cultivar, $2012-14$.

\begin{tabular}{|c|c|c|c|c|c|c|}
\hline Cultivar & $\begin{array}{c}\text { Fruit } \\
\text { wt (g) }\end{array}$ & $\begin{array}{c}\text { Total phenolics } \\
\text { (Folin-Ciocalteu } \\
\text { method, mg gallic } \\
\text { acid eq/100 g dry wt) }\end{array}$ & $\begin{array}{l}\text { Total phenolics } \\
\text { (Glories method, mg gallic } \\
\text { acid eq/100 g dry wt) }\end{array}$ & $\begin{array}{l}\text { Tartaric esters } \\
\text { (mg caffeic acid } \\
\text { eq/100 g dry wt) }\end{array}$ & $\begin{array}{c}\text { Flavonols } \\
\text { (mg quercetin } \\
\text { eq/100 g dry wt) }\end{array}$ & $\begin{array}{c}\text { Total anthocyanins } \\
\text { (cyanidin } 3 \text {-rutinoside/100 g } \\
\text { dry wt) }\end{array}$ \\
\hline \multicolumn{7}{|l|}{2012} \\
\hline Cristalina & 8.8 & 412 & 349 & 145 & 78 & 111 \\
\hline Skeena & 7.6 & 575 & 549 & 249 & 122 & 113 \\
\hline Significance & $* *$ & $* * * *$ & $* * * *$ & $* * * *$ & $* * * *$ & NS \\
\hline \multicolumn{7}{|l|}{2013} \\
\hline Cristalina & 11.3 & 554 & 477 & 176 & 104 & 272 \\
\hline Skeena & 11.3 & 667 & 576 & 240 & 111 & 282 \\
\hline Significance & NS & $* * * *$ & $* * * *$ & $* * * *$ & $*$ & NS \\
\hline \multicolumn{7}{|l|}{$2014^{z}$} \\
\hline Cristalina & 9.7 & 615 & 563 & 187 & 155 & 317 \\
\hline Skeena & 11.4 & 799 & 754 & 256 & 188 & 462 \\
\hline Significance & $*$ & $* * * *$ & $* * * *$ & $* * * *$ & $* *$ & $* * *$ \\
\hline
\end{tabular}

${ }^{\mathrm{Z}}$ It should be noted that a significant interaction was observed between P fertigation and cultivar for the 2014 growing year. Interaction means are reported in Table 3.

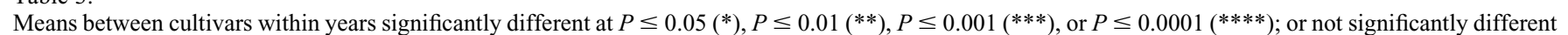
(NS). 
provides data on the levels of total phenolics, tartaric esters, flavonols, and total anthocyanins for two cherry cultivars ('Skeena' and 'Cristalina') grown in the Okanagan region of British Columbia as affected by different irrigation and fertilization strategies, and can serve as a resource for other comparative work.

\section{Literature Cited}

Ali, L., B.W. Alsanius, A.K. Rosberg, B. Svensson, T. Nielsen, and M.E. Olsen. 2012. Effects of nutrition strategy on the levels of nutrients and bioactive compounds in blackberries. Eur. Food Res. Technol. 234:33-44.

Allen, R.G., L.S. Pereira, D. Raes, and M. Smith. 1998. Crop evapotranspiration: Guidelines for computing crop water requirements. FAO Irrigation and Drainage Paper 56. FAO, Rome, Italy.

Anttonen, M.J. and R.O. Karjalainen. 2009. Evaluation of means to increase content of bioactive phenolic compounds in soft fruits. Acta Hort. 839:309-314.

Atkinson, C.J., R. Nestby, Y.Y. Ford, and P.A.A. Dodds. 2005. Enhancing beneficial antioxidants in fruits: A plant physiological perspective. Biofactors 23:229-234.

Ballistreri, G., A. Continalla, A. Gentile, M. Amenta, S. Fabroni, and P. Rapisarda. 2013. Fruit quality and bioactive compounds relevant to human health of sweet cherry (Prunus avium L.) cultivars grown in Italy. Food Chem. 140:630-638.

Bartolini, S., A. Leccese, C. Lacona, L. Andreini, and R. Viti. 2014. Influence of rootstock on fruit entity, quality and antioxidant properties of fresh apricots (cv. 'Pisana'). New Zeal. J. Crop Hort. 42:265-274.

Boivin, D., S. Lamy, S. Lord-Dufour, J. Jackson, E. Beaulieu, M. Cote, A. Moghrabi, S. Barette, D. Gingras, and R. Beliveau. 2009. Antiproliferative and antioxidant activities of common vegetables: A comparative study. Food Chem. 112:374-380.

British Columbia Ministry of Agriculture and Lands. 2010. Integrated fruit production guide for commercial fruit growers. Interior district, British Columbia Ministry of Agriculture and Lands, Victoria, BC, Canada.

Boyer, J. and R.H. Liu. 2003. Antioxidants of apples. New York Fruit Quarterly 11(4):11-15.

Boyer, J. and R.H. Liu. 2004. Apple phytochemicals and their health benefits. Nutr. J. 3:5-19.

Caprio, J.M. and H.A. Quamme. 2006. Influence of weather on apricot, peach and sweet cherry production in the Okanagan Valley of British Columbia. Can. J. Plant Sci. 86:259-267.

Diaz-Mula, H.M., S. Castillo, D. MartinezRomero, D. Valero, P.J. Zapata, F. Guillen, and M. Serrano. 2008. Sensory, nutritive and functional properties of sweet cherry as affected by cultivar and ripening stage. Food Sci. Technol. Intl. 15:535-543.

Engin, H., F. Sen, G. Pamuk, and Z. Gökbayrak. 2009. Investigation of physiological disorders and fruit quality of sweet cherry. Eur. J. Hort. Sci. 74:118-123.

Erdman, J.W., Jr., D. Balentine, L. Arab, G. Beecher, J.T. Dwyer, J. Folts, J. Harnly, P. Hollman, C.L. Keen, G. Mazza, M. Messina, A. Scalbert, J. Vita, G. Williamson, and J. Burrowes. 2007. Flavonoids and heart health: Proceedings of the ILSI North America Flavonoids Workshop, May 31-June 1, 2005, Washington, DC. J. Nutr. 137:718S-737S.
Ferretti, G., T. Bacchetti, A. Belleggia, and D. Neri. 2010. Cherry antioxidants: From farm to table. Molecules 15:6993-7005.

Foyer, C.H. and J.M. Fletcher. 2001. Plant antioxidants: Colour me healthy. Biologist (London) 48:115-120.

Gao, L. and G. Mazza. 1995. Characterization, quantitation and distribution of anthocyanins and colourless phenolics in sweet cherries. J. Agr. Food Chem. 43:343-346.

Harrison, J.E., B.D. Oomah, M.S. Diarra, and C. Ibarra-Alvarado. 2013. Bioactivities of pilot scale extracted cranberry juice and pomace. $\mathrm{J}$. Food Process. Preserv. 37:356-365.

Kader, A.A. 2002. Pre- and postharvest factors affecting fresh produce quality, nutritional values and implications for human health. Proc. Intl. Congress Food Prod. Q1ty. Life 1(4-8):109-119.

Li, X.M., X.L. Li, and A.G. Zhou. 2007. Evaluation of antioxidant activity of the polysaccharides extracted from Lycium barbarum fruits in vitro. Eur. Polym. J. 43:488-497.

Liu, Y., X. Liu, F. Zhong, R. Tian, K. Zhang, X. Zhang, and T. Li. 2011. Comparative study of phenolic compounds and antioxidant activity in different species of cherries. J. Food Sci. 76(4): C633-C638.

Lutz, M., J. Hernández, and C. Henríquez. 2015. Phenolic content and antioxidant capacity in fresh and dry fruits and vegetables grown in Chile. CYTA J. Food 13(4):541-547.

McCune, L.M., C. Kubota, N.R. Stendell-Hollis, and C.A. Thomson. 2011. Cherries and health: A review. Crit. Rev. Food Sci. Nutr. 51:1-12.

McCutchan, H. and K.A. Shackel. 1992. Stemwater potential as a sensitive indicator of water stress of prune tree (Prunus domestica L. cv. French). J. Amer. Soc. Hort. Sci. 117:607-611.

Measham, P.F., S.A. Bound, A.J. Gracie, and S.J. Wilson. 2012. Crop load manipulation and fruit cracking in sweet cherry (Prunus avium L.). Adv. Hort. Sci. 26:25-31.

Munns, R. and M. Tester. 2008. Mechanism of salinity tolerance. Annu. Rev. Plant Biol. 59:651-681.

Neilsen, D., G. Neilsen, S. Guak, and T. Forge. 2016. Consequences of deficit irrigation and crop load reduction on plant water relations, yield and quality of 'Ambrosia' apple. HortScience 51:98-106.

Neilsen, D., C.A.S. Smith, G. Frank, W. Koch, Y. Alila, W.S. Merritt, W.G. Taylor, M. Barton, J.W. Hall, and S.J. Cohen. 2006. Potential impacts of climate change on water availability for crops in the Okanagan Basin, British Columbia. Can. J. Soil Sci. 86:921-936.

Neilsen, G. H., D. Neilsen, and T. Forge. 2017. Environmental limiting factors for cherry production, p. 189-222. In: J. Querro-Garcia, A. Iezzoni, J. Pulawska, and G. Lang (eds.). Cherries, botany, production and uses. Centre for Agriculture and Bioscience International, Oxford, UK

Neilsen, G.H., D. Neilsen, S. Guak, and T. Forge. 2015. The effect of deficit irrigation and crop load on leaf and fruit nutrition of fertigated 'Ambrosia'/‘M.9' apple. HortScience 50:13871393.

Neilsen, G.H., D. Neilsen, F. Kappel, and T. Forge. 2014. Interaction of irrigation and soil management on sweet cherry productivity and fruit quality at different crop loads that simulate those occurring by environmental extremes. HortScience 49:215-220.

Neilsen, G.H., D. Neilsen, F. Kappel, P. Toivonen, and L. Herbert. 2010. Factors affecting establishment of sweet cherry on Gisela 6 rootstock. HortScience 45:939-945.
Neilsen, G.H., D. Neilsen, P. Toivonen, and L. Herbert. 2008. Annual bloom-time phosphorus fertigation affects soil phosphorus, apple tree phosphorus nutrition, yield, and fruit quality. HortScience 43:885-890.

Parchomchuk, P., R.C. Berard, and T.W. Van der Gulik. 1996. Automatic irrigation scheduling using an electronic atmometer, p. 1099-1104. In: C.R. Camp, E.J. Sadler, and R.E. Yordu (eds.). Proceedings International Conference on Evapotranspiration and irrigation scheduling. American Society of Agricultural Engineers, San Antonio, TX.

Rice-Evans, C., N. Miller, and G. Paganga. 1997. Antioxidant properties of phenolic compounds. Trends Plant Sci. 2:152-159.

Ripoll, J., L. Urban, M. Staudt, F. Lopez-Lauri, L.P.R. Bidel, and N. Bertin. 2014. Water shortage and quality of fleshy fruits: Making the most of the unavoidable. J. Expt. Bot. 65:4097-4117.

SAS. 2006. SAS for mixed models. 2nd ed. SAS Institute, Cary, $\mathrm{NC}$

Seeram, N.P., R.A. Momin, M.G. Nair, and L.D. Bourquin. 2001. Cyclooxygenase inhibitory and antioxidant cyaniding glycosides in cherries and berries. Phytomedicine 8:362-369.

Serradilla, M.J., M.F. Aksic, G.A. Manganaris, S. Ercisli, D. Gonzalez-Gomez, and D. Valero. 2017. Fruit chemistry, nutritional benefits and social aspects of cherries, p. 430-441. In: J. Quero-Garcia, Amy Iezzoni, Joanna Pulawska, and Gregory Lang (eds.). Cherries, botany, production and uses. CAB Intl., Oxford, UK.

Singleton, V.L. and J.A. Rossi. 1965. Colorimetry of total phenolics with phosphomolybdicphosphotungstic acid reagents. Amer. J. Enol. Viticult. 16:144-158.

Stopar, M., U. Bolcina, A. Vanzo, and U. Vrhovsek. 2002. Lower crop load for cv. Jonagold Apples (Malus $\times$ domestica Borkh.) increases polyphenol content and fruit quality. J. Agr. Food Chem. 50(6):1643-1646.

Topp, G.C. and W.D. Reynolds. 1998. Time domain reflectometry: A seminal technique for measuring mass and energy in soil. Soil Tillage Res. 47:125-132.

Usenik, V., P. Orazem, and F. Stampar. 2010. Low leaf to fruit ratio delays fruit maturity of 'Lapins' sweet cherry on Gisela 5. Scientia Hort. 126:33-36.

Valavanidis, A., T. Vlachogianni, A. Psomas, A. Zovoili, and V. Siatis. 2009. Polyphenolic profile and antioxidant activity of five apple cultivars grown under organic and conventional agricultural practices. Intl. J. Food Sci. Technol. 44:1167-1175.

Vashisth, T., M.A. Olmstead, J. Olmstead, and T.A. Colquhoun. 2017. Effects of nitrogen fertilization on subtropical peach fruit quality: Organic acids, phytochemical content, and total antioxidant capacity. J. Amer. Soc. Hort. Sci. 142:393-404.

Velioglu, Y.S., G. Mazza, L. Gao, and B.D. Oomah. 1998. Antioxidant activity and total phenolics in selected fruits, vegetables, and grain products. J. Agr. Food Chem. 46:41134117.

Wang, Y. and M. Frei. 2011. Stressed food: The impact of abiotic environmental stresses on crop quality. Agr. Ecosyst. Environ. 141:271286.

Wittneben, U. 1986. Soils of the Okanagan and Similkameen Valleys. Technical report 10, British Columbia Soil Survey 52. British Columbia Ministry of the Environment, Victoria, BC, Canada. 